\title{
Comparative efficacy and safety of mometasone furoate dry powder inhaler and budesonide Turbuhaler ${ }^{\circledR}$
}

\section{To the Editor:}

BousQUET et al. [1] recently compared the efficacy and safety of mometasone furoate dry powder inhaler (MF DPI) and budesonide DPI (Turbuhaler $\mathbb{R}$ ) for the treatment of moderate persistent asthma. They concluded that lower doses of MF DPI appeared to be more effective than a clinically recommended dose of budesonide DPI, while providing a comparable degree of safety.

For several reasons we do not agree with this conclusion. Experiences gained during the last decade have taught us that the greatest amount of care must be taken in the design of studies where the relative efficacy of inhaled steroids are to be investigated. Not least has it repeatedly been seen that the dose-response curves for these drugs on most antiasthma variables are very flat, which means that traditional doseresponse studies are acceptable for comparisons of relative efficacy only if several doses are selected over a wide dose range [2]. For budesonide, several studies have shown that a four-fold difference in dose may be necessary for ensuring statistically significant dosedifferences [3, 4]. In the study by BousQuet et al. [1] only one dose of budesonide Turbuhaler $\mathbb{R}$ $\left(800 \mu \mathrm{g} \cdot \mathrm{day}^{-1}\right)$ was compared to three doses of MF DPI $\left(200,400\right.$ and $\left.800 \mu \mathrm{g} \cdot \mathrm{day}^{-1}\right)$. The budesonide dose was as high as the highest dose of MF, so no information of what a lower dose of budesonide could have achieved in this patient population could be obtained. The lack of multiple doses of budesonide also turned out to be less ideal as the $800 \mu \mathrm{g}$ dose of MF did not show any improvement over the $400 \mu \mathrm{g}$ dose. Thus, for MF DPI also, a dose-response curve could not be constructed. Overall, the design chosen cannot prove any relative efficacy ratio between the two drugs.

It is also noticeable that one-third of the patients were already treated with similar doses of budesonide (mean doses $663 \mu \mathrm{g}$ ) when entering the study and for these patients a further improvement on $800 \mu \mathrm{g}$ could hardly be expected. Patient expectations regarding treatment benefit would thus be nonexistent in this group as compared to other patients given the new inhaler. Also, one would have anticipated a more thorough compliance check, given the delicacy in comparing a new but similar inhaled steroid DPI treatment with an established one.

The most serious flaw is of course that the study was not blinded to the patients and that no double dummy technique was used. This might be difficult to obtain in dose-response studies, but alternative designs are available; in a double-blind study in asthmatic children utilizing dose-reduction of bude-

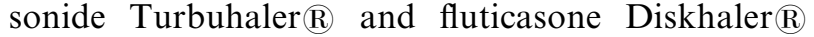
every 5 weeks, minimal effective doses of the two preparations could be calculated [5]. The study showed that there was no significant difference in clinical efficacy between the two preparations at similar doses. This result should be kept in mind as there have been claims that mometasone DPI and

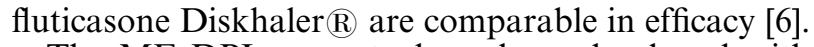

The MF DPI seems to have been developed with Turbuhaler $(\mathbb{R}$ as a close prototype. It differs, however, in some crucial dose-activating characteristics, e.g. the turning of the cap activates the dose-metering unit. More importantly, the MF DPI is labelled in delivered doses, whereas budesonide Turbuhaler $\mathbb{R}$ is labelled in metered doses. Thus, the $800 \mu \mathrm{g}$ mometasone DPI dose that was used in the study by BousQueT et al. [1] was not compared with an identical dose of budesonide, but rather $560 \mu \mathrm{g}$, these are the doses that are delivered from the respective inhalers. This difference between the two preparations was not stated in the article, but may contribute to any claim regarding higher potency for the MF DPI versus other inhaled formulations.

Regarding the safety characteristics of mometasone furoate dry powder inhaler, the authors claim that both drugs provide a comparable degree of safety based on the lack of effect on the hypothalamicpituitary-adrenal axis. However, these results are what would be expected given the low sensitivity of morning cortisol assessment to detect differences between treatment regimens [2]. In the present study, this is evidenced by the same cortisol suppression following treatment with the lowest mometasone furoate dry powder inhaler dose $\left(200 \mu \mathrm{g} \cdot \mathrm{day}^{-1}\right)$ as at baseline, where patients were given $400-800 \mu \mathrm{g} \cdot \mathrm{day}^{-1}$ of other inhaled steroids. It still remains to be proven if the low systemic availability, claimed after inhalation of mometasone furoate [7], can be translated into low systemic effects, or if any pharmacologically active metabolite might explain the hypothalamicpituitary-adrenal effects seen after inhaled doses of mometasone furoate $[8,9]$.

\section{L-G. Carlsson, S. Edsbäcker}

AstraZeneca R\&D, S-221 87 Lund, Sweden.

\section{References}

1. Bousquet J, D'Urzo A, Hebert J, et al. Comparison of the efficacy and safety of mometasone furoate dry 
powder inhaler to budesonide Turbuhaler. Eur Respir $J$ 2000; 16: 808-816.

2. Boulet LP, Cockcroft DW, Toogood J, Lacasse Y, Baskerville J, Hargreave FE. Comparative assessment of safety and efficacy of inhaled corticosteroids: Report of a Committee of the Canadian Thoracic Society. Eur Respir J 1998; 11: 1194-1210.

3. Busse WW, Chervinsky P, Condemi J, et al. Budesonide delivered by Turbuhaler is effective in a dosedependent fashion when used in the treatment of adult patients with chronic asthma. J Allergy Clin Immunol 1998; 101: 457-463.

4. Pauwels RA, Löfdahl CG, Postma DS, et al. Effect ofinhaled formoterol and budesonide on exacerbations of asthma. N Engl J Med 1997; 337: 1405-1411.

5. Agertoft L, Pedersen S. A randomized, double-blind dose reduction study to compare the minimal effective dose of budesonide Turbuhaler and fluticasone propionate Diskhaler. J Allergy Clin Immunol 1997; 99: $773-780$.
6. $\mathrm{O}^{\prime}$ Connor BJ, Bonnaud G, Luna JM, SanchezBorges M, Lutsky BN. Comparison of mometasone furoate (MF) administered by dry powder inhaler (DPI) with fluticasone propionate (FP) administered by Diskhaler in patients with moderate persistent asthma. Eur Respir J 1999; 14: Suppl. 30, 197s.

7. Affrime MB, Cuss F, Padhi D, et al. Bioavailability and metabolism of mometasone furoate following administration by metered-dose and dry-powder inhalers in healthy human volunteers. J Clin Pharmacol 2000; 40: $1227-1236$.

8. Affrime MB, Kosoglou T, Thonoor CM, Flannery BE, Herron JM. Mometasone furoate has minimal effects on the hypothalamic-pituitary-adrenal axis when delivered at high doses. Chest 2000; 118: $1538-1546$.

9. Lipworth BJ, Jackson CM. Safety of inhaled and intranasal corticosteroids-Lessons for the new millenium. Drug Safety 2000; 23: 11-33.

\section{Lung cancer in young females}

\section{To the Editor:}

We read with interest the article by LIENERT et al. [1]. Based on data of the clinical cancer registry at the Lungenklinik Heckeshorn, Berlin, 1986-1995, the authors examined whether young female lung cancer patients ( $\leq 45$ yrs of age, $n=96)$ differ from all other lung cancer patients $(n=4,843)$ with respect to risk factors, histology and clinical features. They found a higher proportion of adenocarcinomas (38\%) and carcinoids in young females. Other main characteristics of young females were a high proportion of eversmokers $(88 \%)$ and a large number of patients who reported a first degree relative with lung cancer (13\%). We would like to add our recent findings of a largescaled, case-control study of lung cancer conducted in Germany from 1990-1996 [2, 3], which aimed to investigate risk factors for lung cancer in young adults. This study included 251 young patients and 280 population controls ( $\leq 45$ yrs of age), as well as 2,009 older cases and 2,039 older controls $(55-69$ yrs of age). Adenocarcinomas were more frequent in young males $(41 \%)$ and young and older females $(44 \%$ and $47 \%$, respectively) than in older males $(28 \%)$. Differences in histology between age groups could be explained, in part, by differences in smoking patterns. However, there are still unknown factors that appear to favour the development of adenocarcinoma in the young [3]. A history of lung cancer in first degree relatives was associated with a 2.6 -fold (95\% confidence interval (CI) 1.1-6.0) increased risk in the young, while no elevated risk was observed in the older group (odds ratio $=1.2$ 95\% CI 0.9-1.6). Additional evidence for an age-specific genetic predisposition in lung cancer was recently provided by GAUDERMAN and MORRISON [4]. About $80 \%$ of our young female cases were current smokers, demonstrating a 30-fold increased lung cancer risk compared to never-smoking young females [2]. As stated by
LIENERT et al. [1], smoking is the main risk factor for lung cancer in young females. This was recently supported in a pooled analysis of European casecontrol studies of lung cancer in young females [5], where $84 \%$ of female patients aged $40-45$ yrs could be attributed to active smoking.

\section{Kreuzer*, H.E. Wichmann ${ }^{\#}$}

*Federal Office of Radiation Protection, Institute of Radiation Hygiene and ${ }^{\#}$ GSF-Institute of Epidemiology, Ingolstädter Landstr. 1, 85764 Neuherberg, Germany.

\section{References}

1. Lienert T, Serke M, Schönfeld N, Loddenkemper R. Lung cancer in young females. Eur Respir J 2000; 16: 986-990.

2. Kreuzer M, Kreienbrock L, Gerken M, et al. Risk factors for lung cancer in young adults. Am J Epidemiol 1998; 147: 1028 - 1037.

3. Kreuzer M, Kreienbrock L, Müller KM, Gerken M, Wichmann HE. Histologic types of lung carcinoma and age at onset. Cancer 1999; 85: $1958-1965$.

4. Gauderman WJ, Morrison JL. Evidence for agespecific genetic relative risks in lung cancer. $\mathrm{Am}$ J Epidemiol 2000; 151: 41 - 49.

5. Boffetta P, Kreuzer M, Benhamou S, et al. Risk of lung cancer from tobacco smoking among young women from Europe. Int J Cancer 2001; 91: 745-746.

\section{From the authors:}

The valuable data of our colleagues M. Kreuzer and H.E. Wichmann support the main results from our own series. Yet it is remarkable that in their patients, adenocarcinoma in older females $(55-69$ yrs of age) 